\title{
Temporal aggregation: time use methodologies applied to residential electricity demand
}

Article

Accepted Version

Creative Commons: Attribution-Noncommercial-No Derivative Works 4.0

Torriti, J. (2020) Temporal aggregation: time use methodologies applied to residential electricity demand. Utilities Policy, 64. 101039. ISSN 0957-1787 doi: https://doi.org/10.1016/j.jup.2020.101039 Available at https://centaur.reading.ac.uk/79651/

It is advisable to refer to the publisher's version if you intend to cite from the work. See Guidance on citing.

To link to this article DOI: http://dx.doi.org/10.1016/j.jup.2020.101039

Publisher: Elsevier

All outputs in CentAUR are protected by Intellectual Property Rights law, including copyright law. Copyright and IPR is retained by the creators or other copyright holders. Terms and conditions for use of this material are defined in the End User Agreement.

www.reading.ac.uk/centaur 
Central Archive at the University of Reading

Reading's research outputs online 


\title{
Temporal aggregation: Time use methodologies applied to residential electricity demand
}

\begin{abstract}
Understanding what constitutes peaks and identifying areas of effective load shifting intervention becomes vital to the balancing of demand and supply of electricity. Whilst there is information about the aggregate level of consumption of electricity, little is known about residential peak demand and what levels of flexibility might be available. Specifically, methodologies linking people's activities and residential electricity load profiles are typically under-investigated. The overall aim of this paper is to introduce methodologies which capture the variation in sequences of activities taking place at times of peak electricity demand. The paper introduces a set of analytical tools which can be deployed when examining time use survey data in energy demand research. It presents the state of the art with modelling load profiles based on time use data and design methodological modifications to improve modelling around peak periods. It is demonstrated how the methodologies presented in the paper can be applied to specific understanding of distributional effects of Time of Use tariffs. The paper discusses issues associated with validation between synthetic data, survey data and electricity metered data and concludes with policy implications and some observations for future research.
\end{abstract}

\section{Keywords}

Demand Side Response; Electricity demand; Load profiles; Markov chains; Residential energy demand; Time of Use tariffs; Time use; 


\section{Introduction}

Peak electricity demand is becoming an increasingly significant problem for UK networks as it causes imbalances between demand and supply with negative impacts on system costs and the environment. The residential sector is responsible for about one third of overall electricity demand and up to $40 \%$ of peak demand (DECC, 2013). During peak demand, electricity prices in wholesale markets could fluctuate from less than $€ 0.04 / \mathrm{kWh}$ to as much as $€ 0.35 / \mathrm{kWh}$ (Torriti, 2015). In the future the peak problem is expected to worsen due to the integration of intermittent renewables in the supply mix as well as high penetration of electric vehicles and electric heat pumps.

Understanding what constitutes peaks and identifying areas of effective load shifting intervention becomes vital to the balancing of demand and supply of electricity. Whilst there is information about the aggregate level of consumption of electricity, little is known about residential peak demand and what levels of flexibility might be available. Specifically, methodologies linking people's activities and residential electricity load profiles are typically under-investigated.

The overall aim of this paper is to introduce methodologies which capture the variation in sequences of activities taking place at times of peak electricity demand for temporal aggregation purposes. This is with a view to identify clusters of residential users which might provide flexibility for peak shifting intervention. Specific objectives consist of (i) introducing methodologies for analysing variation of activities taking place at times of residential peak electricity demand; and (ii) identifying clustering techniques in order to determine groups of users whose sequences of activities might provide flexibility for peak shifting intervention.

Weekdays domestic electricity load profiles are cyclical with recurrent morning and evening peaks. This paper derives examples of electricity demand profiles for UK residential consumers from 10minute resolution time use activity data from the UK 2014-2015 Office for National Statistics Time Use Survey. This enables to derive information about occupancy and synchronisation of activities. Sequence analysis is used to mine activities at periods of peak electricity demand. This paper will put forward techniques to cluster respondents according to sequences of activities and analyse to what extent appliance-specific control variables explain activities at specific times of the day. Findings on sequence analysis are expected to feed into algorithms for explicit Demand Side Response (DSR), implicit DSR (through Time of Use tariffs) or automated demand management.

After this introduction, the paper briefly reviews research on time use data and residential electricity demand (Section 2). It introduces a set of analytical tools which can be deployed when examining time use survey data in energy demand research (Section 3). It presents the state of the art with modelling load profiles based on time use data and design methodological modifications to improve modelling around peak periods (Section 4). It is demonstrated how the methodologies presented in the paper can be applied to specific understanding of distributional effects of Time of 
Use tariffs (Section 5). The paper discusses issues associated with validation between synthetic data, survey data and electricity metered data (Section 6), before concluding with some observations for future research (Section 7).

\section{Time use data and residential electricity demand}

Researchers have been investigating for the most effective methods and data to measure the timing of residential electricity demand for some time. Various models have been deployed, from stochastic predictions of appliance use to weather-related deterministic models. Based on reviews in the area of residential electricity demand (Suganthi and Samuel, 2011; Swan and Ugursal, 2009), the most frequently collected data consist of type of building, occupants' income, appliance ownership and bill-related price of electricity. These variables capture the size of electricity demand, but are not able to explain in-day load profiles as they do not reveal when different sociodemographic groups of people are at home and what they are doing at peak and off-peak times.

The starting point of methodologies based on time use data is that the timing of people's activities plays a vital role in explaining the timing of residential electricity demand and the potential effects of ToU tariffs. This approach is in line with recent inter-disciplinary studies which consist of employing time use data (i.e. tracking residential users in and out of the household) and linking them to residential electricity demand based on previous work by Wood and Newborough (2003) and Firth et al (2008) who distinguished between deterministic and stochastic timing of appliance use. Time use data have been used before in energy demand research in the UK (Richardson et al, 2008; Richardson et al, 2010; Torriti et al, 2015), France (Wilke et al, 2013), Spain (LópezRodríguez, 2013) and Sweden (Widén and Wäckelgård, 2010; Widén et al, 2009). The general approach of these studies tends to rely on either time use diary data or stochastic models. Whilst time use data have proven effective at re-generating electricity load profiles for domestic dwellings, they have never been used to infer distributional impacts of dynamic tariffs. Whilst Markov chains have proven effective at re-generating electricity load profiles for domestic dwellings, their temporal distribution at peak time needs to be addressed further (Duffy et al, 2010; Torriti, 2014), as explained in Section 4 of this paper. Recent work on time use data and peak residential electricity demand has focused on comparing active occupancy across different countries (Torriti, 2012); measuring flexibility through synchronisation, occupancy and number of time use activities (Torriti et al, 2015); analysing specific activities, such as laundry (Anderson, 2016); and measuring time dependence of social practices (Torriti, 2017).

In essence, both analytical tools applied to time use diary data and modelling of residential electricity load profiles deserve further methodological reflection as explained in the section below. 


\section{Time use survey data: analytical tools}

Weekdays domestic electricity load profiles are cyclical with recurrent morning and evening peaks. This suggests that methods and data able to capture the activities which take place in everyday life offer high value to research on residential electricity demand. As explained in Section 2, time use data can shed light on the activities underpinning energy demand. This section shows methodological approaches and techniques to derive electricity demand profiles for UK residential consumers from time use data.

Two specific techniques are introduced below. First, peak occupancy variance estimates are estimated with a view to give an indication of how much occupancy varies within peak periods. Second, sequence analysis techniques can be deployed with a view to examine activity patterns across different socio-demographic characteristics of those individuals carrying out frequent activities.

\subsection{Peak occupancy variance and synchronicity index}

Peak occupancy variance measures by how much occupancy varies within peak periods as

$\beta_{t, t+1}=\frac{\omega_{t}}{\omega_{t+1}}$, where $\beta_{t, t+1}$ is the variance measured between time intervals at peak time and $\omega_{t}$ is the level of active occupancy (i.e. number of people in the household not sleeping) at the time $t$.

The synchronicity index measures the extent to which the same activities are taking place across the population. It is generally based on the Shannon's $H$ entropy index: $H_{t}=-\sum_{i=1}^{\lambda} \gamma_{t i} \ln \left(\gamma_{t i}\right)$, where $\lambda$ is the number of different states, $i$ (i.e. activity codes considered), $t$ is the time of interest (i.e. 10-minute time slot) and $\gamma_{t i}$ is the number of individuals who are in state $i$ at $t$.

\subsection{Sequence analysis}

Innovative ways of analysing time-use activities consider these not as happening in isolation, but rather as sequences. Sequence analysis can be implemented with a view to identify the most frequent successions of activities at different times of the day. Sequence analysis, which is common for analysing internet transaction, has not been applied extensively to energy demand. In the past sequence analysis techniques, like Optimal Matching, have been applied in the social sciences (Abbott, 1984), but have also been criticised for misrepresenting the duration of key parameters (Elzinga, 2003). In order to obviate this problem, matching techniques can be deployed using duration inputs from time use data with a view to identifying similarities in sequences of activities. Data mining algorithms (i.e. VISUAL-TimePAcTS1 and CLUSTAL) facilitate the automatic identification of sequences across the data. Sequence analysis could be applied among activities taking place at peak time (one 10 minute interval to the next) with a view to understand the most dominant activities taking place at peak time. This is equivalent to analysing a time 
window containing an activity pattern, minimum and maximum occurrences of the activity, and number of people that perform it. This enables bottom-up clustering of people in terms of commonalities in activities during the same periods of the day.

\subsection{Activity schemes}

Table 1-Time use activities and associated appliances, including electrical load and proportion of dwellings with appliance (Adapted from Powells et al., 2014)

\begin{tabular}{|c|c|c|c|}
\hline Activity & $\begin{array}{l}\text { Employed } \\
\text { electricity } \\
\text { appliances }\end{array}$ & $\begin{array}{l}\text { Typical electrical } \\
\text { load (kW) }\end{array}$ & $\begin{array}{l}\text { Proportion of dwellings } \\
\text { with appliance (\%) }\end{array}$ \\
\hline \multirow{5}{*}{$\begin{array}{l}\text { Preparing food and } \\
\text { washing the dishes }\end{array}$} & Hob & 2.40 & 46.3 \\
\hline & Oven & 2.13 & 61.6 \\
\hline & Microwave & 1.25 & 85.9 \\
\hline & Kettle & 2.00 & 97.5 \\
\hline & Dish washer & 1.13 & 33.5 \\
\hline \multirow[t]{2}{*}{ Washing } & Electric shower & 9.00 & 67 \\
\hline & $\begin{array}{l}\text { Central heating } \\
\text { pump }\end{array}$ & 0.60 & 90 \\
\hline Cleaning & Vacuum & 2.00 & 93.7 \\
\hline \multirow[t]{4}{*}{ Washing clothes } & Tumble dryer & 2.50 & 41.6 \\
\hline & Washing machine & 0.41 & 78.1 \\
\hline & Washer dryer & 0.79 & 15.3 \\
\hline & Iron & 1.00 & 90 \\
\hline \multirow{3}{*}{$\begin{array}{l}\text { Watching TV and listening } \\
\text { to the radio }\end{array}$} & TV & 0.12 & 97.7 \\
\hline & TV receiver box & 0.03 & 93.4 \\
\hline & Radio & $\mathrm{n} / \mathrm{a}$ & $\mathrm{n} / \mathrm{a}$ \\
\hline Using computer & $\begin{array}{l}\text { Personal } \\
\text { computer/console }\end{array}$ & 0.14 & 70.8 \\
\hline
\end{tabular}

Activity schemes are probability conversions form time use data to electricity consumption profiles. This is a pre-modelling, parameter-intense exercise which typically involves parameter gathering and activity schemes. Table 1 provides an example of time use activities and associated appliances, including electrical load and proportion of dwellings with appliance.

Empirical-based activity schemes originate from linking time use codes with appliance use, as shown in Figure 1. Time-use activity data are subsequently converted to electricity load profiles 
through conceptual activity schemes (i.e. assuming basic electricity demand patterns for every end-use category). Alternatively the connections between household and appliance use could be based on household type (Fisher et al, 2015).

Figure 1- Example of activity scheme linking time use codes with appliance use
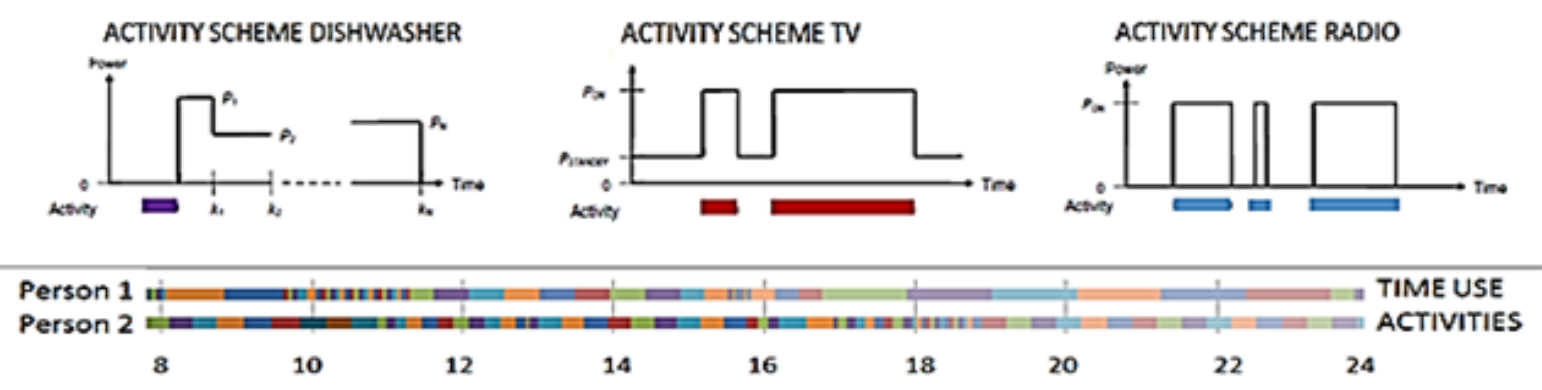

In their modelling work, Widén and Wäckelgård (2010) suggest that activity schemes can be classified according to: (i) power demand not defined by activities (i.e. cold appliances, modelled as a base load); (ii) power demand constant during activity (i.e. cooking, ironing, cleaning, use of TV, audio appliances and computer); (iii) power demand constant after activity (i.e. dish-washing, washing and drying); and (iv) activities with time-dependent power demand (i.e. lighting with power varying with time dependent on day lighting levels). However, Mc Kenna et al. (2017) note that to a wealth of data on the timing of activities and individual appliance usage (Zimmermann et al., 2012), does not correspond a clear relationship between the two.

\section{Modelling load profiles from time use data}

Large time use surveys have the merit of being nationally representative and offer a wealth of attributes in terms of socio-economic variables and geographical location of respondents. However, in most developed countries they are not conducted frequently. For instance, in the UK large National Time Use Surveys are only performed once a decade. This calls for more cost-effective representations of time use data, including synthetic time use data. In the UK, one of the most often cited time use models was developed by the University of Loughborough. This domestic electricity demand model is based on occupant time-use data and maps occupant activity to appliance use and stochastically creates synthetic demand data with a 1minute time resolution.

The use of Markov Chain modelling is widespread in this research area. At one level, Markov chains determine the probability of a household's electricity demand taking place at different times of the day. At another level, Markov chains generate occupancy profiles through a stochastic process making use of probability distributions. 
Markov chains develop transitional probability matrixes where the transition from one discrete state to another discrete state is represented in terms of its probability. The transition probabilities vary with time to reproduce daytime variations.

An individual performs one of the time use activities in every time step $\alpha=1, \ldots, N_{\alpha}$. When moving from $\alpha \mathrm{k}$ to $\alpha+1$ there is a transition probability $p_{i j}(\alpha)$ of going from state $i$ to $j$ (including the probability $p_{i i}(\alpha)$ of remaining in state $\left.I\right)$.

Figure 2 provides an example of how state transition (from one activity to another or to the same activity) occurs in each time step. The probability $p_{i j}(\alpha)$ will vary as activity patterns because a random uniform number is generated and compared to the transition probabilities to determine which transition is taking place. The example is drawn on three activities only for simplicity. The fact that transition probabilities vary over the day is particularly significant for peak periods which experience higher velocity of transition between time steps (hence the introduction of Hybrid Monte Carlo modelling as explained below). An assumption needs to be made regarding the initial activity, which typically involves attributing 'sleeping' at the early hours of the night. 
Figure 2-Example of state transition in 4 different time steps (for 3 activities)

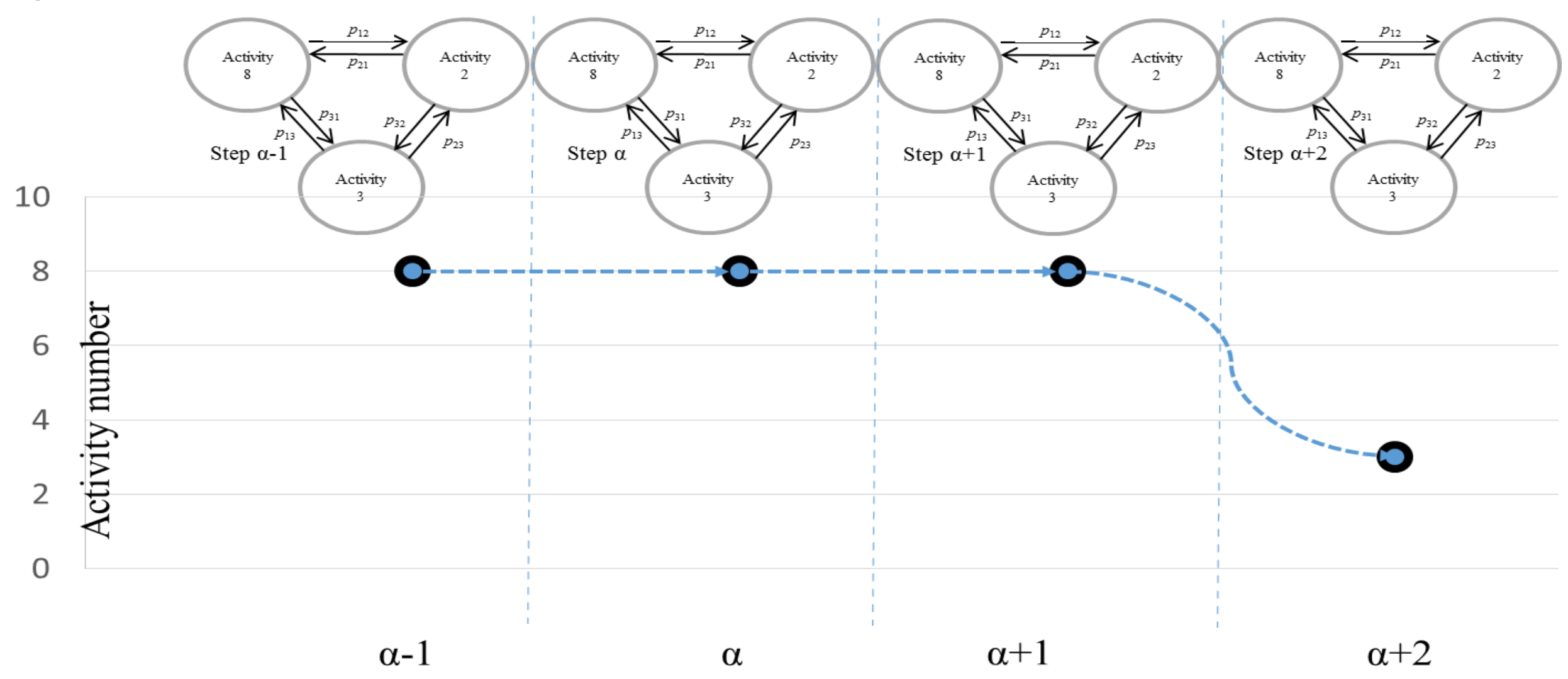




\subsection{Hybrid Monte Carlo modelling for peak periods}

The Markov chain technique is suited to modelling systems where the current state of a sequence is highly correlated to the state immediately preceding it and where a large sample size of data exists. It is applied as an autoregressive process which can generate synthetic sequences for modelling stochastic residential electricity consumption. Hence, Markov chains can be applied to compare individual metered activities with modelled load profiles. The stochastic Markov-chain process generates high-resolved synthetic activity sequences to which appliance loads are connected to create power demand data for a variety of end-uses. Whilst Markov chains have proven effective at re-generating electricity load profiles for domestic dwellings in terms of the magnitude component of the load profile, it has been noted that the temporal distribution can be improved significantly (Duffy et al, 2010). In order to obviate this problem, this paper suggests that Hybrid Monte Carlo techniques could be deployed. Hybrid Monte Carlo techniques could introduce an auxiliary momentum vector so that modelled demand would move in larger steps during peak periods. This is to reflect the fact that activities at peak time are less correlated and converge to the target distribution more rapidly. Given a set of activities $\{|n\rangle\}$, the activities at peak time $t$ may be expanded as:

$|\psi(\mathrm{t})\rangle=\sum_{n} a_{n}(\mathrm{t})|\mathrm{n}\rangle \quad$ where $\quad a_{n}(t)=\langle\mathrm{n} \mid \Psi(\mathrm{t})\rangle$.

The coefficients $a_{n}(t)$ consist of both time-independent parameters (e.g. appliance efficiencies from activity schemes) and time-dependent dummies (e.g. peak and off-peak times). The introduction of the auxiliary momentum vector will enable to capture the higher velocity of activity transitions at peak time and will address an existing mismatch between Markov chains and load profiles in terms of simultaneity of appliance use at peak time. The presence of a higher speed transition probability of moving from one state to the next for peak periods will feed into the activity schemes, hence modelling a reality in which people can carry out an activity at the time, but have multiple electric loads on at the same time.

\subsection{Parameters}

The first step when choosing parameter values from the data sources detailed in Section 3 is to find an 'average' parameter set that gives a mean energy use by an appropriate geography -i.e. country or region, depending on the spatial scope of the study- to all households in the time-use dataset. Estimates of standard powers and runtime for electrical appliances can be gathered making use of product tests, depending on the types of appliances available at different times of the day.

Because it may be difficult to obtain consistent data on the actual scope of appliances throughout a large population of households, the estimates obtained by using average parameters would be 
extremely approximate. To reflect the distribution of different appliance sets, the second step will consist of applying frequencies of actual appliance diffusion based on data from country-specific National Household and Environment Surveys. Specific parameter values can also be attributed to proportions of household types, age of building and floor area using country-by-country data from the Buildings Performance Institute Europe. In order to determine the lighting power scheme, Europe-wide data on daylight and solar radiation can be obtained from the Satel-Light database.

\subsection{Clustering}

Data mining softwares can be employed to facilitate the automatic identification of same time use patterns across the data. They can be implemented among activities taking place at peak and offpeak times (one 10-minute interval to the next).

This is equivalent to analysing (peak and off-peak) time windows containing an activity pattern, minimum and maximum occurrences of the activity, and number of people that perform it. This process enables bottom-up clustering of people in terms of commonalities in energy-related activities during the same periods of the day as shown in Figure 3. Clustering algorithms (e.g. through the implementation of the CLUSTAL software) can be used to define the size and composition of the cluster.

\section{Figure 3-Clustering time use activities}

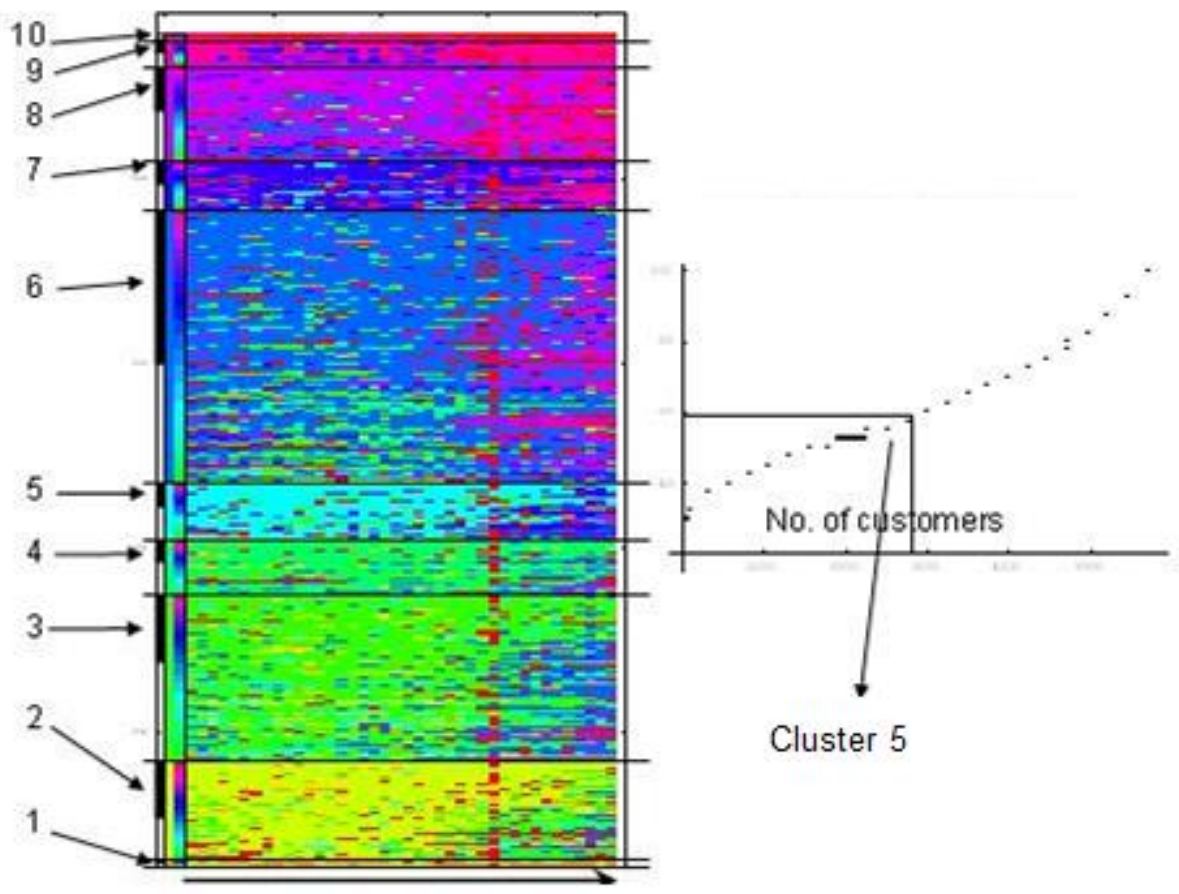

Time of the day 
The clusters are typically determined using a finite mixture technique, which employs a Gaussian distribution for each feature, and for each cluster. In other words the probability of a value $y_{j, k}$ in cluster $g$ is taken as

$$
f_{j, g}\left(y_{j, k}\right)=\frac{1}{\sigma_{j, g}} \frac{1}{\sqrt{2 \pi}} \exp \left[-\frac{1}{2}\left(\frac{y_{j, k}-\mu_{j, g}}{\sigma_{j, g}}\right)^{2}\right]
$$

where $\mu_{j, g}$ is the mean and $\sigma_{j, g}$ the standard deviation of the distribution.

Each cluster population will be described by its mixing proportion and a normal distribution for each feature (McLachlan \& Peel, 2004).

The parameters are optimised by an unsupervised learning process known as the EM algorithm. Once calibrated, the clusters will be numbered so that clusters between which customers most often pass will be adjacent. This numbering will also put the clusters in order of their average daily use. Because the clusters represent actual activity patterns, they provide a more accurate and responsive picture of end-users' activities than possible with any demographic classification.

\section{Applications on Time of Use tariffs}

The roll-out of smart meter across all 26 million GB households will transform how consumers buy and use energy. Electricity smart meters should remove the need for profiling in electricity as they can provide accurate half-hourly meter readings. Part of this will involve the enrolment of a large number of consumers to new Time of Use (ToU) tariffs. However, the impact of more cost reflective ToU tariffs will vary between consumers. For example, those who consume electricity during the more expensive peak periods and those who are unable to change their consumption patterns (e.g. elderly pensioners and heating) could end up paying significantly more. The nationallevel integration of dynamic tariffs (including ToU tariffs) has the potential to bring about significant reductions in prices, expand demand for renewables and limit carbon emission from dirty power plants. This poses questions around who will benefit and who will lose from increases in peak tariffs. Specifically, vulnerable households may be subject to increase in prices due to a combination of lower income and time scarcity. ToU tariffs offer significant potential benefits to the system by enabling responsive electricity demand and reducing peaks. For example, they could reduce the need for new generation and network capacity. However, the impact of more costreflective pricing will vary between consumers. In particular, those who consume electricity at more expensive peak periods, and who are unable to change their consumption patterns, could end up paying significantly more. Understanding the distributional effects of ToU tariffs becomes vital to ensuring affordability of energy bills, at the same time as making demand more flexible. Whilst 
there is significant research on fuel poverty in relation to aggregate level of consumption of electricity, little is known about the effects of dynamic tariffs on different socio-demographic groups. Time use methodologies presented in Section 4 can fill this gap.

Applied work on time use data can analyse the distributional effects of ToU tariffs with a view to identify clusters of users which might significantly benefit or be disadvantaged through the provision of demand flexibility. Analysis on the distributional effects of ToU pricing is very limited. For instance, the Centre for Sustainable Energy (2015) carried out analysis of the distributional effects of ToU tariffs. This showed that most consumers would see relatively small changes in bills, but some could see increases in bills of up to $20 \%$. However, this study did not consider the effects on different sociodemographic groups and did not consider whether households indeed had flexibility in terms of how their schedules are structured. Applications of time use methodologies imply deploying data on people's activities to understand the economic effects of ToU tariffs on different groups of end-users. Specifically, this approach can assess the feasibility of time use data applications for deriving electricity load profiles; cluster residential end-users according to the timing of their energy-related activities; and measure the distributional effects of ToU tariffs on different clusters of end-users.

Figure 4- Survey data, parameter data and Time of Use tariffs simulation

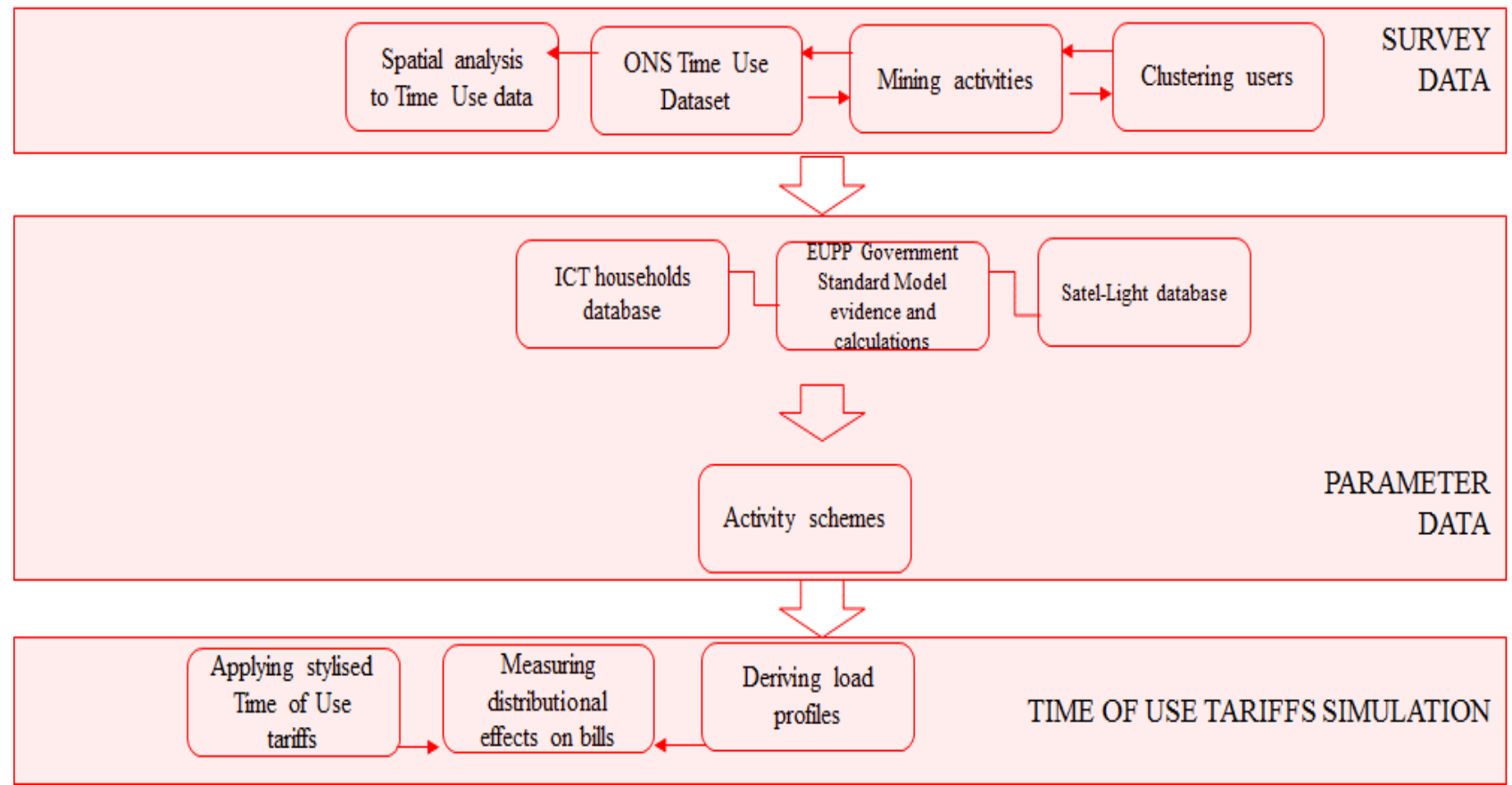

This approach derives electricity demand profiles for UK residential consumers from time use and parameter data and activity schemes. Figure 4 provides an overview of the data flows, distinguishing between survey data, parameter data and time use simulation. Time Use Survey provides 10-minute resolution information on people's activities. These are analysed in relation to 
spatial and sociodemographic variables. Specific attention is paid to factors which are relevant to energy consumption and may vary significantly across different income groups. These include weekends/weekdays, winter/summer, urban/rural, households with/without children. With regards to ToU tariffs simulation, applying ToU tariffs to the average consumption behaviour of households in each group provides an indication of which groups may benefit from reduced electricity bills and which may face higher costs, absent behaviour change. Stylised ToU tariffs, as established, for example, by the Centre for Sustainable Energy (2014), can be applied to the load profiles derived for each cluster. Four stylised tariffs (standard flat rate tariff; higher tariff only for the evening peak period; higher tariff for evening peak and cheaper rate over night; and cheaper flat rate for weekends) can be modified marginally to be revenue neutral for all clusters. The modified tariffs are then applied to each load profile which is subject to be rebased to the cluster's average load. This enables the isolation of the relative benefits and costs for the groups and households within this sample.

\section{Validation of synthetic, survey and metered data}

Work capturing simultaneously smart metering (e.g. meter-level electricity consumption) data and time use activities is mostly missing in research. A couple of exceptions consist of work carried out in projects carried out by Électricité de France and the METER project being developed at the University of Oxford. Durand-Daubin (2013) measures people's activities, appliances use, and electric consumption for 60 households in France deploying quantitative questionnaire, qualitative interviews, activity diaries, and real time energy consumption with sensor measurements. Overall, the methods provide a consistent description of the intensity and time of use of the three appliances studied even if some variations were found, depending on the indicator and appliance studied. Grünewald \& Layberry (2015) combine the collection of time-use information with detailed electricity readings at the household level. The instrumentation and data collection methodology promises to improve on the insight gained from their collection in separation, reduces the cost of collection and minimises the burden on participants. 
Figure 5-Survey and synthetic data, parameter data and metered data

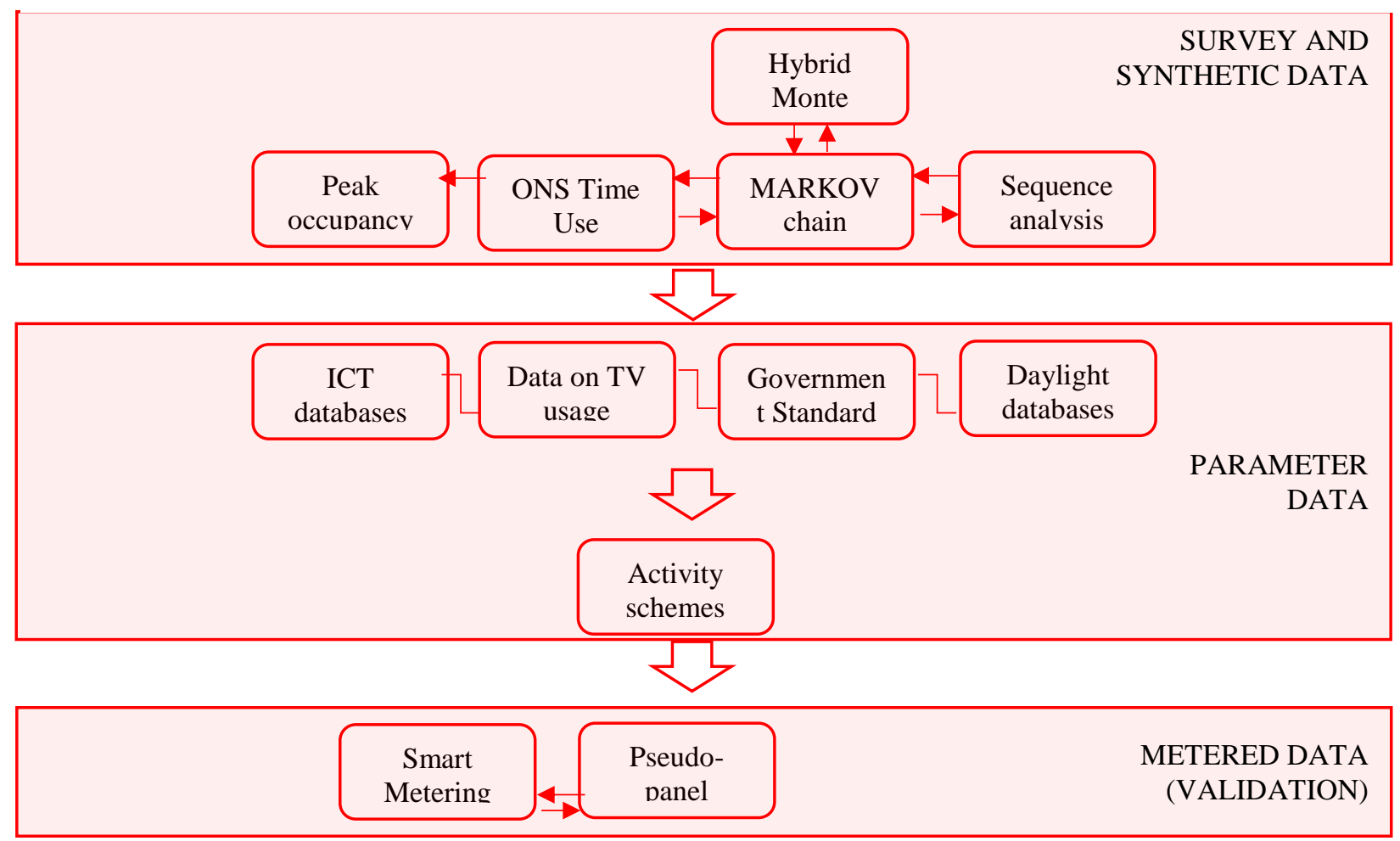

Figure 5 illustrates the steps associated with different types of analysis associated with survey and synthetic data, parameter data and metered data. Validation is critical in terms of verifying both the transition from time use activities to load profiles and synthetic representations of time use data. Modelled time use or occupancy data can be verified against actual time use data. For instance, López-Rodríguez et al (2013) validate their application of the Loughborough model (as explained in Section 4) to the Spanish Time Use Survey. The validation of synthetic and metered data presents similar challenges (Ramírez-Mendiola et al, 2017). With time use data the main challenge is that samples from smart metering data and time use surveys are not populated by the same respondents. This challenge is not uncommon in research attempting to join datasets and can be overcome by extracting salient statistical properties. In methodologies developed around time use data, this becomes less critical provided that the unit of analysis consists of the activities, rather than the individuals who perform the activities. This is possible especially if empirical work relying on time use data is backed by conceptual interpretations of activities as 'social practices' (Strengers, 2012). Figure 5 suggests the creation of a pseudo-panel by grouping sociodemographic variables in the time use dataset according to contained in the metered electricity demand dataset.

The comparison between time use and metered consumption data involves correlation analysis taking one statistic observation as one household and computing average rate or duration of use 
by day of experiment. The main tool to compare daily load curves will be the Normalized Variation Factor presented in Capasso et al (1994) as:

Normalized Variation Factor $=\frac{\sum_{i}^{n}\left(D_{\text {Mar }}(i)-D_{\text {meas }}(i)\right)^{2}}{n\left(\left(\frac{1}{n}\right) \sum_{i}^{n} D_{\text {meas }}(i)\right)^{2}}$

Where $D_{\text {Mar }}(i)$ is synthetic demand from Markov chains and $D_{\text {meas }}(i)$ is metered demand. Variance analysis (ANOVA) and Duncan means comparisons are also calculated: (i) to assess the differences between the mean frequencies of revealed (i.e. time use) and measured usage of the appliances; (ii) to estimate differences between average durations by day; and (iii) to compare the mean electricity consumption of the appliance with standard parameters.

\section{Conclusions and policy implications}

In energy demand research there is a long tradition of methodologies developed to model residential electricity demand. In this larger literature, work on residential electricity load profiles and levels of flexibility are emergent research areas. Peak electricity demand is becoming an increasingly significant problem for power networks as it causes imbalances between demand and supply with negative impacts on system costs and the environment (Element Energy and DeMontfort University, 2012). Residential heat pumps and electric vehicles could further add to peak load contribution (Strbac et al, 2010). Existing research on storage, flexible systems and demand side participation cover significant aspects of peak electricity demand and flexibility. Data on peak demand is extremely relevant as its reliable provision has significant implications for system costs and decarbonisation options. Whilst there is information about the aggregate level of consumption of peak electricity demand, little is known about the activities, behaviours and practices which underpin this phenomenon. The paper presented methodologies which can combine time use data and metered data with a view to inform on the practices and sequences of activities taking place at times of peak electricity demand.

It is concluded that work on the identification of determinants of electricity demand can contribute significantly to appropriate modelling and may serve to assess future policy pathways up to 2050 . The methodologies outlined in this paper move the state of the art of research on residential electricity demand in three ways. First, the scope and size of time use studies offers the opportunity to pose largely generalizable questions about what triggers electricity demand behind the meter. This paper presented examples of large applications of activity-based data applied to residential electricity demand, making use of thousands of time-use records. Hence, studies using nationally representative time use data and applying the methodologies introduced in this paper have the potential to make a very authoritative assessment of what constitutes load profiles. Second, this paper introduced novel concepts of synchronicity and active occupancy through the 
development of new metrics, such as entropy indexes and occupancy variances. This is a significant step forward compared with recent and ongoing metering-only studies (e.g. from Low Carbon Network Fund projects in the UK), as it enables to establish the causes for the timing of residential electricity demand and potential for intervention based on what people do. Third, this paper applies sequence analysis, optimal matching and clustering as innovative ways to improve time use research and to potentially allow significant comparison across different socio-economic groups of end-users.

The policy implication of this paper are twofold and regard both explicit and implicit DSR programmes.

Firstly, this paper developed sequence analysis methodologies which will potentially trigger future work on automated demand controllers' algorithms, which may contribute to explicit DSR programmes. The integration of explicit DSR programmes has the potential to bring about significant reductions in prices, expand demand for renewables and limit carbon emission from dirty power plants. However, the electricity market has an underdeveloped residential DSR market as information about load profiles and shiftable loads is missing (Torriti et al, 2010). The effectiveness of future DSR penetration in the residential sector depends on accurate information about the timing of electricity demand and an understanding of what causes peaks in load profiles. This is because any price (e.g. dynamic pricing) or technology (e.g. smart appliances with delayers and remote controlling) will have to be developed starting from current practices (Wardle et al, 2013). In the future, load management may comprise automated load controllers whose algorithms will require information about the activities of clusters of end-users.

Secondly, with regards to implicit DSR, this paper demonstrated the potential value of time use methodologies applied to ToU tariffs, particularly with reference to the distributional effects these might trigger on different income groups of end-users. This means that incentives to change consumer behaviour and mitigate the magnitude of these peaks, such as Time of Use tariffs, offer significant potential benefits to the system as a whole. This includes reducing the need for new generation and network capacity, as well as enabling responsive electricity demand. Time of Use tariffs would also help ensure that relative household costs reflect the impact of their consumption levels and behaviour on the energy system. This flexibility comes at a price which ultimately has to be paid by households. In a negative scenario, the most vulnerable consumers will pay more for their bills because of ToU tariffs and information about how people consumer energy through the time use data and methodologies presented in this paper will become vital for policy-makers and utilities. There might also be solutions which do not penalise vulnerable consumers. For instance, a recent study commissioned by Citizens Advice suggests that critical peak rebates have been successful in other countries at reducing the risk of consumers' being worse off from changes to 
time of the day tariffs. Under critical peak rebates, rather than charging a higher price during peak events, rebates are paid to customers for load reductions relative to an estimated baseline consumption level (Brattle Group and UCL, 2017). Lack of flexibility also comes at a price. Studies have estimated that, if flexibility is not pursued, and with $30 \mathrm{GW}$ of intermittent renewables and inflexible nuclear capacity in the system, up to $25 \%$ of wind energy may need to be curtailed to enable fossil fuel generation provide the required ancillary services (University of Cambridge and Imperial College London, 2016). Moreover, the National Infrastructure Commission (2016) estimates the value of the technical potential of the flexibility market at around £8 billion per year for flexible technologies such as generation, interconnection, network technologies, demand side response, and storage.

\section{References}

Abbott, A. (1984). Event sequence and event duration: Colligation and measurement. Historical Methods, 17, 192-204.

Anderson, B. (2016). Laundry, energy and time: Insights from 20 years of time-use diary data in the United Kingdom. Energy Research \& Social Science, 22, 125-136.

Brattle Group and UCL (2017). The Value of TIME OF USE Tariffs in Great Britain: Insights for Decision-makers. Accessed 1 November 2017, https://www.citizensadvice.org.uk/Global/CitizensAdvice/Energy/The\%20Value\%20of\%20TOU\%20 Tariffs\%20in\%20GB\%20-\%20Volume\%20I.pdf

Capasso, A., Grattieri, W., Lamedica, R., \& Prudenzi, A. (1994). A bottom-up approach to residential load modeling. Power Systems, IEEE Transactions, 9(2), 957-964.

Centre for Sustainable Energy (2015), Investigating the potential impacts of Time of Use tariffs on domestic electricity customers, Report to Ofgem.

DECC (2013). United Kingdom housing energy fact file. London: Department of Energy \& Climate Change.

Duffy, A., McLoughlin, F., Conlon, M. (2010), The Generation of Domestic Electricity Load Profiles through Markov chain Modelling. 3rd International Scientific Conference on Energy and Climate Change 7-8 October 2010 Athens, Greece. 
Durand-Daubin, M. (2013). Household activities through various lenses: crossing surveys, diaries and electric consumption. Behavior, Energy \&. Climate Change Conference, 17-20 November 2013, Sacramento, U.S.

Element Energy and DeMontfort University (2012). Demand side response in the non-domestic sector.

Elzinga, C. H. (2003). Sequence similarity-a non-aligning technique. Sociological Methods \& Research, 31, 3-29.

Fischer, D., Härtl, A., \& Wille-Haussmann, B. (2015). Model for electric load profiles with high time resolution for German households. Energy and Buildings, 92, 170-179.

Firth, S., Lomas, K., Wright, A., Wall, R., 2008. Identifying trends in the use of domestic appliances from household electricity consumption measurements. Energy and Buildings 40, 926-936.

Grünewald, P., \& Layberry, R. (2015). Measuring the relationship between time-use and electricity consumption. ECEEE-2015 European council for an energy efficient economy, 1439-50.

López-Rodríguez, M. A., Santiago, I., Trillo-Montero, D., Torriti, J. and Moreno-Munoz, A. (2013). Analysis and modeling of active occupancy of the residential sector in Spain: An indicator of residential electricity consumption. Energy Policy, 62, 742-751.

McKenna, E. J., Higginson, S., Grunewald, P., \& Darby, S. (2017). Simulating residential demand response: Improving socio-technical assumptions in activity-based models of energy demand. Energy Efficiency.

McLachlan, G., Peel, D. (2004). Finite mixture models. John Wiley \& Sons.

National Infrastructure Commission (2016). Smart power. Accessed 1 November 2017, https://www.gov.uk/government/uploads/system/uploads/attachment_data/file/505218/IC_Energy_ Report_web.pdf

Ramírez-Mendiola, J. L., Grünewald, P., \& Eyre, N. (2017). The diversity of residential electricity demand-A comparative analysis of metered and simulated data. Energy and Buildings, 151, 121131. 
Richardson, I., Thomson, M., Infield, D. (2008). A high-resolution domestic building occupancy model for energy demand simulations. Energy and Buildings, 40, 1560-1566.

Richardson, I. W., Thomson, A. M., Infield, D., Clifford, C. (2010). Domestic electricity use: A highresolution energy demand model. Energy and Buildings, 42, 1878-1887.

Skea, J., et al. (2013). Investing in a Brighter Energy Future: Energy Research and Training Prospectus. RCUK.

Strengers, Y. (2012). Peak electricity demand and social practice theories: Reframing the role of change agents in the energy sector. Energy Policy, 44, 226-234.

Strbac, G., et al. (2010). Benefits of Advanced Smart Metering for Demand Response based Control of Distribution Networks. Imperial College and Energy Networks Association (ENA).

Suganthi, L., Samuel, A. (2011). Energy models for demand forecasting-A review. Renewable and Sustainable Energy Reviews 16, 1223-1240.

Swan, L. G., Ugursal, V. I. (2009). Modeling of end-use energy consumption in the residential sector: A review of modeling techniques. Renewable and Sustainable Energy Reviews, 13, 18191835.

Torriti, J. (2012) Demand side management for the European Supergrid: occupancy variances of European single-person households. Energy Policy, 44. pp. 199-206.

Torriti, J. (2014). A review of time use models of residential electricity demand. Renewable and Sustainable Energy Reviews, 37, 265-272.

Torriti, J. (2015). Peak energy demand and demand side response. Routledge, Abingdon.

Torriti, J. (2017). Understanding the timing of energy demand through time use data: time of the day dependence of social practices. Energy Research \& Social Science, 25. pp. 37-47.

Torriti, J., Hanna, R., Anderson, B., Yeboah , G. and Druckman, A. (2015). Peak residential electricity demand and social practices: Deriving flexibility and greenhouse gas intensities from time use and locational data. Indoor and Built Environment, 24 (7), 891-912. 
Torriti, J., Hassan, M. G. and Leach, M. (2010). Demand response experience in Europe: policies, programmes and implementation. Energy, 35, 1575-1583.

University of Cambridge and Imperial College London (2016). Delivering future-proof energy infrastructure. Accessed 1 November 2017, http://www.biee.org/wpcms/wpcontent/uploads/Future-proof_energy_infrastructure_Imp_Cam_Feb_2016_NIC.pdf

Wardle, R., Barteczko-Hibbert, C., Miller, D., \& Sidebotham, E. (2013). Initial Load Profiles from CLNR Intervention Trials. Customer-Led Network Revolution.

Widén, J., Lundh, M., Vassileva, I., Dahlquist, E., Ellegård, K., Wäckelgård, E. (2009). Constructing load profiles for household electricity and hot water from time-use data-Modelling approach and validation. Energy and Buildings, 41, 753-768.

Widén, J., Wäckelgård, E. (2010). A high-resolution stochastic model of domestic activity patterns and electricity demand. Applied Energy, 87, 1880-1892.

Wilke, U., Haldi, F., Scartezzini, J. L., \& Robinson, D. (2013). A bottom-up stochastic model to predict building occupants' time-dependent activities. Building and Environment, 60, 254-264.

Wood, G. Newborough, M. (2003). Dynamic energy-consumption indicators for domestic appliances: environment, behaviour and design. Energy and Buildings 35, 821-841.

Zimmermann, J. P., Evans, M., Griggs, J., King, N., Harding, L., Roberts, P., \& Evans, C. (2012). Household Electricity Survey: A study of domestic electrical product usage. Intertek Testing \& Certification Ltd. 